\title{
Utilização de História em Quadrinhos como ferramenta de avaliação no processo de ensino- aprendizagem de Botânica no Clube de Ciências
}

\author{
Irismar Neves da $\mathrm{Paz}^{1}$ \& Juliane Marques-de-Souza ${ }^{1,2}$
}

1. Universidade Estadual de Roraima (UERR). Rua Sete de Setembro 231, Canarinho CEP 69306-530C, Boa Vista, RR, Brasil.

2. Programa de Pós-graduação em Ensino de Ciências e Matemática (PPGEC)/Universidade Estadual de Roraima (UERR).

Email: irismar_neves@hotmail.com; juliane.marques.souza@gmail.com

Recebido em : 13 de julho de 2016. Aceito em: 29 de agosto de 2016. Publicado PDF em: 31 de agosto de 2016

\section{RESUMO}

Utilização de História em Quadrinhos como ferramenta de avaliação no processo de ensino- aprendizagem de Botânica no Clube de Ciências. O presente artigo teve como objetivo geral avaliar a elaboração de histórias em quadrinhos (HQs) como ferramenta de avaliação do ensino aprendizagem do conteúdo de botânica no Clube de Ciências, realizada com seis estudantes do $2^{\circ}$ ano do Curso Técnico em Manutenção e Suporte em Informática do período matutino do Ensino Médio Integrado profissionalizante (EMIP) de uma escola da rede pública de ensino do município Mucajaí, Roraima. Neste sentido, para embasamento da pesquisa foi utilizada a teoria da aprendizagem significativa. Para a coleta de dados foram elaboradas histórias em quadrinho pelos alunos participantes do Clube de Ciências focando conceitos botânicos estudados durante os encontros do Clube. A análise de desempenho da ferramenta avaliativa foi realizada por meio de parâmetros previamente elaborados. Os resultados obtidos revelam que a HQ, além de fazer parte do cotidiano dos alunos, apresenta-se como uma ferramenta eficaz, podendo ser utilizada para avaliar os discentes de forma qualitativa, contribuindo para que o professor consiga detectar se a aprendizagem ocorreu de maneira significativa. As HQs permitem a manifestação da aprendizagem por meio de diferentes linguagens além de abrirem espaço para a criatividade. Os resultados apontados concordam com a ideia de que a avaliação vai além do que a realização de provas e atribuições de notas e visa sempre à melhoria da qualidade da aprendizagem.

PALAVRAS CHAVE: História em quadrinho, Ferramenta avaliativa, Aprendizagem significativa.

\begin{abstract}
Comic books as an evaluation tool of teaching learning botanical content in the Science Club. This paper aimed to evaluate the development of comic books (comics) as an evaluation tool of teaching learning botanical content in the Science Club, carried out with six students of 2nd year of the Technical Course in Maintenance and Support in Computer Science from morning period of vocational Integrated school (EMIP) a school public school system of the municipality Mucajaí, Roraima. In this sense, for grounding the research was used the theory of meaningful learning. For data collection stories were drawn in comic by participating students of the Science Club focusing on botanical concepts studied during Club meetings. The performance analysis tool of evaluation was performed by previously established parameters. The results show that the HQ, and is part of students' daily life, presents itself as an effective tool and can be used to assess students in a qualitative way, helping the teacher can detect if learning occurred significantly. The HQs allow the manifestation of learning through different languages as well as open space for creativity. The indicated results agree with the idea that the assessment goes beyond the accomplishment of tests and assignments and notes always aims to improve the quality of learning.
\end{abstract}

KEY WORDS: History in comic, evaluative tool, significant learning.

\section{INTRODUÇÃO}

A avaliação no âmbito escolar ainda encontra-se presa ao antigo método avaliativo, fazendo uso da prova como a principal ferramenta, atribuindo valores ao aprendizado dos alunos através de notas. No entanto, a avaliação tem por função diagnosticar as 
dificuldades dos alunos, permitindo ao professor detectar se houve avanço na aprendizagem, possibilitando ao professor fazer uma reflexão de suas aulas e metodologia (Vasconcellos 1998).

A avaliação é de fundamental importância no processo educacional e pode ser feita de várias maneiras. A avaliação deve ser contínua, podendo o professor fazer uso de instrumentos avaliativos que deem liberdade para o aluno aprender e que possam ser utilizados para comparar o que se pretendia alcançar com o que foi alcançado (Sant'anna 1995; Fernandes 2008). As provas, por outro lado, embora frequentes, são elaboradas com questões subjetivas ou objetivas, o que não permite que o professor detecte problemas que dificultem a aprendizagem, como: medo do professor, timidez, dificuldades de assimilar o conteúdo (Sant'anna 1995). Esses aspectos, no entanto, podem levar ao fracasso do aluno.

Para o professor avaliar o aluno de modo satisfatório é necessário diversificar o método de avaliar, fazendo uso de ferramentas que permitam acompanhar a construção do conhecimento de cada discente, identificando suas limitações para que venham progredir de maneira significativa (Rabelo 2009).

Nesse sentido, diversificar os instrumentos avaliativos é uma das alternativas para verificar as dimensões da aprendizagem dos alunos, tendo a função de coletar um maior número de informações úteis sobre a aprendizagem dos discentes (Silva 2013). Nesse sentido, o presente artigo buscou avaliar a utilização de histórias em quadrinhos (HQs) como ferramenta avaliativa do processo de ensino e aprendizagem de botânica em uma Escola Estadual no município de Mucajaí, Roraima, visando novas possibilidades de se avaliar o aprendizado dos alunos.

Os objetivos específicos foram: incentivar os alunos a produzirem histórias em quadrinhos focando o estudo da botânica, através de textos e desenhos; avaliar os conceitos botânicos contidos nas HQs e; estimar a aceitação dos alunos pela produção da história em quadrinho quanto ferramenta de avaliação da aprendizagem.

Assim, tendo em vista a importância de avaliar o ensino e aprendizagem dos alunos, é necessário que o professor entenda que não é preciso abandonar a forma tradicional de avaliar e sim diversificá-la, a fim de evidenciar a construção do conhecimento do aluno. E por fim, conhecer as potencialidades de cada ferramenta avaliativa, de maneira a aplicá-las corretamente, garantindo que seu uso venha expor os aspectos avaliativos demandados pelo professor em cada situação de aprendizagem.

\section{MATERIAL E MÉTODOS}

O presente estudo foi realizado com seis estudantes do $2^{\circ}$ ano do Curso Técnico em Manutenção e Suporte em Informática do período matutino do Ensino Médio Integrado Profissionalizante (EMIP) da escola da rede pública de ensino Escola Padre José Monticone do município Mucajaí, Roraima que participaram das atividades do projeto herborização no ano de 2014, e que continuaram em 2015 no Clube de Ciências. O Clube de Ciências tinha como proposta criar ferramentas didáticas que dessem suporte às aulas teóricas de biologia e promover atividades educativas que auxiliassem os alunos na contextualização do conteúdo.

A história em quadrinho foi solicitada pela pesquisadora e elaborada pelos educandos que utilizaram desenhos manuais, a criação ficou a critério dos estudantes, os quais estiveram presentes nos encontros do Clube de Ciências, realizados uma vez por semana, nas quartas-feiras no horário das $14: 00 \mathrm{hs}$ as $17: 00 \mathrm{hs}$ no período oposto as aulas, funcionando até os dias atuais com seis alunos frequentando os encontros.

A presente pesquisa originou-se de uma sequência de atividades de ensino empregadas com os alunos participantes do Clube de Ciências e que estudavam o conteúdo de botânica. Dentre as atividades realizadas previamente à elaboração das histórias em quadrinhos pode-se citar: a aplicação de dinâmicas em grupo, a aplicação de jogos de tabuleiro; a aplicação da técnica de coleta e herborização. Para produzir as histórias em quadrinhos foram necessários três encontros, os dias não foram consecutivos. Para Identificação dos alunos foram utilizadas abreviações: AL1aluno 1; AL2 - aluno 2; AL3- aluno 3; AL4aluno 4; AL5- aluno 5; AL6- aluno 6.

A pesquisa teve abordagem qualitativa e foi organizada em três etapas: A primeira etapa da pesquisa consistiu na produção das histórias em quadrinhos pelos estudantes do $2^{\circ}$ ano, referentes ao conteúdo de Botânica, objetivando avaliar a história em quadrinho como ferramenta de avaliação de ensino 
aprendizagem de botânica. Nesta etapa os alunos, construíram suas histórias com base no que foi abordado no Clube de Ciências. Para a construção das histórias em quadrinhos os alunos optaram por elaborar manualmente.

A etapa seguinte consistiu na criação de parâmetros para avaliar a história em quadrinho como ferramenta avaliativa do processo de ensino e aprendizagem de botânica. Para a avaliação das HQs foram criados parâmetros avaliativos para os quais foram atribuídos o peso dois $(\operatorname{sim}=2)$ aos casos em que o parâmetro foi atingido e zero quando o parâmetro não foi atingido (não=0), aos parâmetros "quantidade de conceitos citados" e "quantidade de conceitos citados corretamente" foi atribuído o peso 1 (um) para cada conceito. $\mathrm{Na}$ terceira etapa foi realizada a análise da ferramenta, a partir da produção das histórias em quadrinhos elaboradas pelos alunos participantes do projeto herborização desenvolvido no Clube de Ciências, utilizando os parâmetros avaliativos.

\section{RESULTADOS E DISCUSSÃO}

Os parâmetros utilizados para avaliar as HQs como ferramenta de avaliação e a pontuação adquirida pelas histórias elaboradas pelos estudantes estão sumarizadas na tabela 1 .

Para produzir as HQs, os alunos utilizaram folhas de papel $\mathrm{A} 4$, lápis de cor, lápis grafite, borracha. Todos esses materiais são acessíveis aos alunos. As folhas de papel A4 foram dobradas ao meio apresentando o formato de uma pequena revista (Figura 1A), dos seis alunos, apenas o AL3 utilizou folha com pauta para produzir sua HQ (Figura 2A).

Nesse sentido, no que se referiu ao material necessário para produzir as HQs, observou-se que todo o material utilizado pode ser disponibilizado facilmente pela escola, se adequando a realidade dos alunos. Na ausência desse material fornecido pela escola, os alunos podem utilizar as folhas dos seus próprios cadernos e montar uma revistinha.

$\mathrm{Na}$ avaliação referente às abordagens dadas às histórias percebeu-se que, das HQs produzidas pelos alunos do Clube, apenas AL5 e AL6 não conseguiram produzir seus textos com diferentes abordagens, pois tiveram dificuldades para abordar os temas estudados. As demais histórias em quadrinhos elaboradas versaram sobre temas distintos, tais como: reprodução, ambiente em que vive cada grupo de planta, diferenças e divisão do grupo das angiospermas (Figura1B).

Assim, das quatro histórias concluídas, duas expuseram roteiro diferenciado, uma retrata a questão da dúvida e da curiosidade explicando que como esta última, por vezes, colabora na aquisição do conhecimento (Figura 1F). A mesma foi elaborada pelo AL3, que utilizou uma linguagem voltada para jovens, com algumas gírias faladas no seu cotidiano. A outra HQ que também fez uso de um roteiro diferente foi a da AL1, a história apresenta uma abordagem voltada à questão da amizade, fazendo uso também de uma linguagem muito utilizada no dia a dia dos adolescentes, conforme Figura 2F. As histórias de AL2 e AL4 retrataram um romance, utilizando a mesma abordagem, com mesmo roteiro mudando apenas os conceitos que foram abordados.

Especificamente no que se refere à linguagem utilizada na elaboração das histórias, percebeu-se que essa ferramenta avaliativa abriu espaço para diferentes tipos de manifestações verbais, sendo elas da linguagem formal (Figura 2B e C) ou informal.

Essa liberdade no uso da linguagem mostrou-se um dos elementos mais positivos da utilização dessa ferramenta, uma vez que permitiu que os estudantes expressassem seu aprendizado de forma espontânea, contribuindo também para a assimilação do conteúdo. Assim, quando os alunos fizeram a abordagem do conteúdo usando uma linguagem rotineira, eles estavam reelaborando, reestruturando seu conhecimento de maneira que conseguissem expressá-los e de maneira que se pudesse entender.

É importante destacar que a utilização das diferentes linguagens para o ensino contribui para a dinamização do conteúdo exposto na sala de aula, diversificando a prática do ensino da disciplina, permitindo uma melhor compreensão da mensagem que o professor espera que o aluno adquira. A linguagem é um fator fundamental na produção textual, quando expressa de maneira não compreensiva e que não seja clara, a mensagem transmitida pode ser interpretada erroneamente, desviando o verdadeiro sentido da informação (Neves 2012).

As HQs dos AL1, AL2, AL3, AL4 demostraram que a linguagem expressou clareza das ideias. Portanto, ao dar espaço para essa manifestação escrita livre, a HQ permitiu 
que os estudantes utilizassem das ferramentas que dispõem para comunicar. O professor pode, inclusive, utilizar essa ferramenta em parceria com o professor da disciplina de português para avaliar o uso correto de sinais como exclamação, vírgula, ponto final, entre outros.

Tabela 1. Análise dos parâmetros utilizados para avaliar as HQs como ferramenta de avaliação e pontuação adquirida pelas as HQs em todos os parâmetros.

\begin{tabular}{|c|c|c|c|c|c|c|c|}
\hline \multirow{2}{*}{ PARÂMETROS } & \multirow{2}{*}{$\begin{array}{l}\text { VALOR } \\
\text { ATRIBUÍDO A } \\
\text { CADA } \\
\text { PARÂMETRO }\end{array}$} & \multicolumn{6}{|c|}{$\begin{array}{l}\text { PONTUAÇÃO ADQUIRIDA PELAS HQS EM } \\
\text { CADA PARÂMETRO }\end{array}$} \\
\hline & & AL1 & AL2 & AL3 & AL4 & AL5 & AL6 \\
\hline $\begin{array}{l}\text { A ferramenta avaliativa permitiu uma } \\
\text { adequação aos materiais disponíveis na } \\
\text { escola e sala de aula? }\end{array}$ & $\begin{array}{l}\text { Sim }=2 \\
\text { Não }=0\end{array}$ & 2 & 2 & 2 & 2 & 2 & 2 \\
\hline $\begin{array}{l}\text { A ferramenta avaliativa permitiu a } \\
\text { produzir textos com diferentes } \\
\text { abordagens? }\end{array}$ & $\begin{array}{l}\text { Sim }=2 \\
\text { Não }=0\end{array}$ & 2 & 2 & 2 & 2 & 0 & 0 \\
\hline $\begin{array}{l}\text { A ferramenta avaliativa permitiu o uso } \\
\text { de diferentes linguagens como forma de } \\
\text { expressar o aprendizado? }\end{array}$ & $\begin{array}{l}\text { Sim }=2 \\
\text { Não }=0\end{array}$ & 2 & 2 & 2 & 2 & 0 & 0 \\
\hline $\begin{array}{l}\text { A ferramenta avaliativa permitiu } \\
\text { estimular, a fantasia e a curiosidade? }\end{array}$ & $\begin{array}{l}\text { Sim }=2 \\
\text { Não }=0\end{array}$ & 2 & 2 & 2 & 2 & 0 & 0 \\
\hline $\begin{array}{l}\text { A ferramenta avaliativa permitiu a } \\
\text { utilização de uma linguagem clara e de } \\
\text { fácil compreensão? }\end{array}$ & $\begin{array}{l}\text { Sim }=2 \\
\text { Não }=0\end{array}$ & 2 & 2 & 2 & 2 & 0 & 0 \\
\hline $\begin{array}{l}\text { A ferramenta avaliativa permitiu } \\
\text { relacionar de forma correta desenho e } \\
\text { fala, contribuindo para a visualização da } \\
\text { compreensão dos conceitos? }\end{array}$ & $\begin{array}{l}\text { Sim }=2 \\
\text { Não }=0\end{array}$ & 2 & 2 & 2 & 2 & 0 & 0 \\
\hline $\begin{array}{l}\text { A ferramenta avaliativa permitiu } \\
\text { averiguar a aceitabilidade das } \mathrm{HQ} \\
\text { quanto ferramenta de avaliação? }\end{array}$ & $\begin{aligned} \text { Sim } & =2 \\
\text { Não } & =0\end{aligned}$ & 2 & 2 & 2 & 2 & 2 & 2 \\
\hline $\begin{array}{l}\text { A ferramenta avaliativa permitiu } \\
\text { evidenciar as diferentes maneiras de } \\
\text { explicar conceitos? }\end{array}$ & $\begin{array}{l}\text { Sim }=2 \\
\text { Não }=0\end{array}$ & 2 & 2 & 2 & 2 & 0 & 0 \\
\hline $\begin{array}{l}\text { A ferramenta avaliativa permitiu } \\
\text { despertar o interesse do aluno pelo } \\
\text { assunto a ser trabalhado? }\end{array}$ & $\begin{array}{l}\text { Sim }=2 \\
\text { Não }=0\end{array}$ & 2 & 2 & 2 & 2 & 0 & 0 \\
\hline $\begin{array}{l}\text { A ferramenta avaliativa permitiu a } \\
\text { aplicação de conceitos sem consulta em } \\
\text { materiais didáticos, internet? }\end{array}$ & $\begin{array}{l}\text { Sim }=2 \\
\text { Não }=0\end{array}$ & 2 & 2 & 2 & 2 & 0 & 0 \\
\hline $\begin{array}{l}\text { A ferramenta avaliativa permitiu } \\
\text { acompanhar expressivamente } 0 \\
\text { conhecimento consolidado durante a } \\
\text { atividade realizada? }\end{array}$ & $\begin{array}{l}\text { Sim }=2 \\
\text { Não }=0\end{array}$ & 2 & 2 & 2 & 2 & 0 & 0 \\
\hline $\begin{array}{l}\text { A ferramenta avaliativa permitiu detectar } \\
\text { problemas e dificuldades em termos de } \\
\text { aprendizagem? }\end{array}$ & $\begin{aligned} \text { Sim } & =2 \\
\text { Não } & =0\end{aligned}$ & 2 & 2 & 2 & 2 & 0 & 0 \\
\hline $\begin{array}{l}\text { A ferramenta avaliativa permitiu } \\
\text { quantificar as horas utilizadas para } \\
\text { produção textual? }\end{array}$ & $\begin{array}{l}\text { Sim }=2 \\
\text { Não }=0\end{array}$ & 2 & 2 & 2 & 2 & 0 & 0 \\
\hline \multicolumn{2}{|c|}{$\begin{array}{l}\text { Quantidade de conceitos utilizados nas HQs (1 ponto por } \\
\text { item) }\end{array}$} & 7 & 8 & 9 & 7 & 0 & 0 \\
\hline \multicolumn{2}{|c|}{$\begin{array}{l}\text { Número de conceitos corretamente utilizados nas HQs } \\
\text { (1ponto por item) }\end{array}$} & 6 & 8 & 8 & 6 & 0 & 0 \\
\hline \multicolumn{2}{|l|}{ TOTAL } & 39 & 42 & 43 & 39 & 2 & 2 \\
\hline
\end{tabular}


Mel como pode uma planta ser tão pequena? Vamos perguntar o nome dela? É mesmo amiga! Eu sou uma gimnosperma e você uma angiosperma, mas, com é a natureza, eu tenho fruto e flor e você não tem flor e não tem fruto (AL 1).
As histórias em quadrinhos apresentaram também alguns elementos textuais que são necessários para a compreensão, tanto da linguagem verbal, quanto da linguagem não verbal. A presença de narrador no texto é evidente em quatro HQs, pertencentes aos AL1, AL2, AL3, AL4, esse elemento ajuda o leitor a compreender a ordem cronológica dos fatos

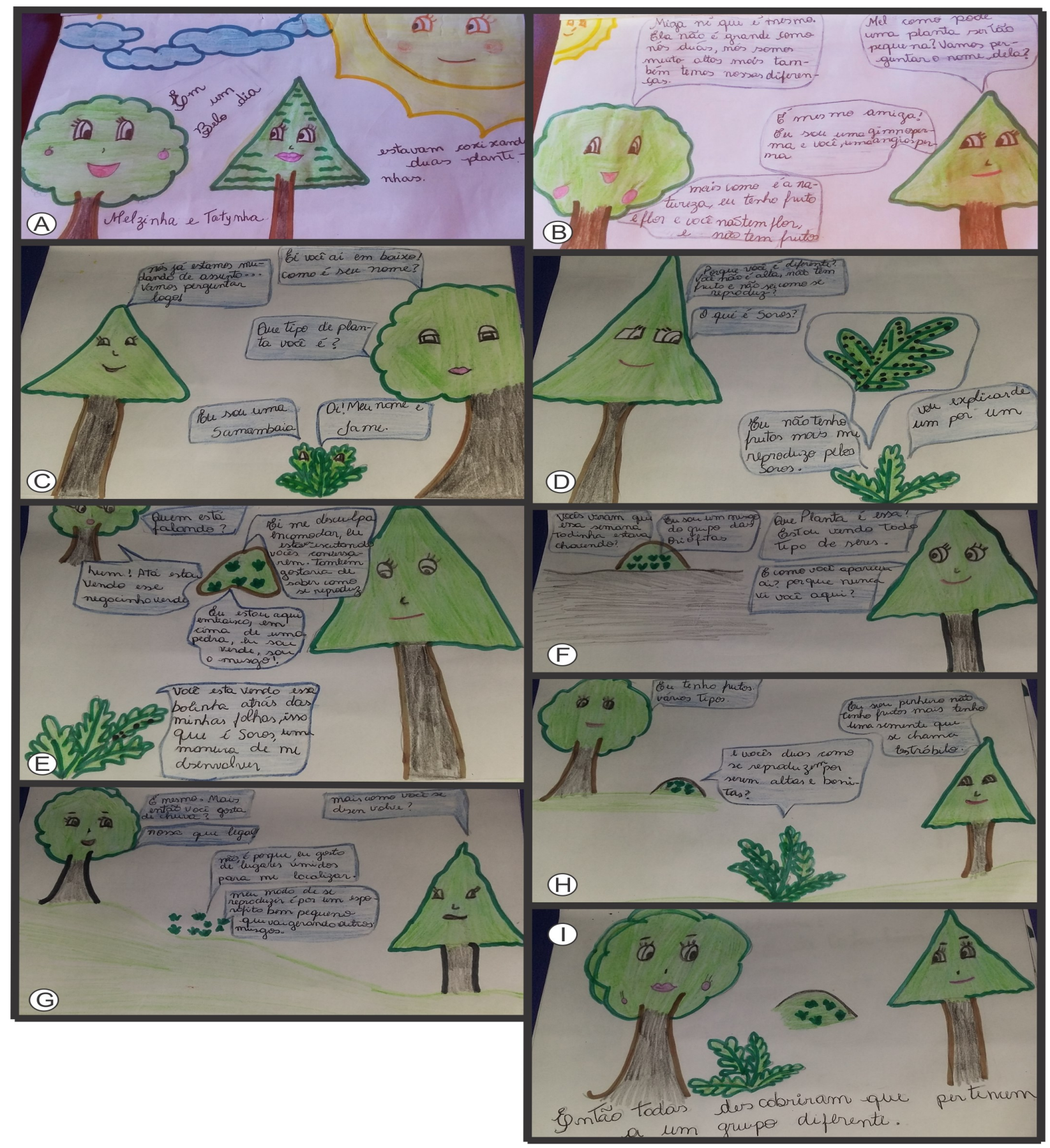

Figura 1. A: imagem da interface da HQ produzida manualmente em folha A4 pela AL2; B: Imagem de uma das histórias em quadrinhos produzidas pelos alunos, apresentando diferentes linguagens como forma de expressar o aprendizado (AL1); C e D: Imagem mostrando as maneiras de explicar os conceitos (AL1); E: imagem que apresenta o erro de conceito contido na HQ da AL1; F: imagem que retrata a questão da curiosidade, que contribui com aquisição do conhecimento; $\mathbf{G}$ e H: imagens que ilustram os conceitos mais frequentes nas HQS elaboradas pelos alunos; I: imagem que retrata há diferença entre os grupos de plantas. 
ocorridos em cada página da história.

O senhor musgo ficou arrasado, pois não haveria como namorar a dona macieira, mas logo ele entendeu por que não poderia ficar com a dona macieira. Enquanto isso, no mesmo jardim, dona samambaia conversa com o seu pinheiro... (AL2).

Tendo em vista a análise do uso de recursos gráficos indicando fala ou pensamento dos personagens, constatou-se o uso de balões para indicar a fala dos personagens. Este recurso estava presentes nas HQs dos AL1,
AL1, AL3 e AL4, em relação ao uso de onomatopeias, apenas o AL3 fez uso desse recurso.

De acordo com Barbosa et al. (2014), as onomatopeias são signos que imitam um som através de caracteres alfabéticos, indicando ação ou ruído, passando a ocupar um papel importante na linguagem dos quadrinhos, apresentadas sempre em letras maiúsculas, grafadas perto do local em que ocorre o som que a representa. Os balões por sua vez, informam o que os personagens estão falando, ou seja, o balão é uma intersecção entre imagem e palavra.

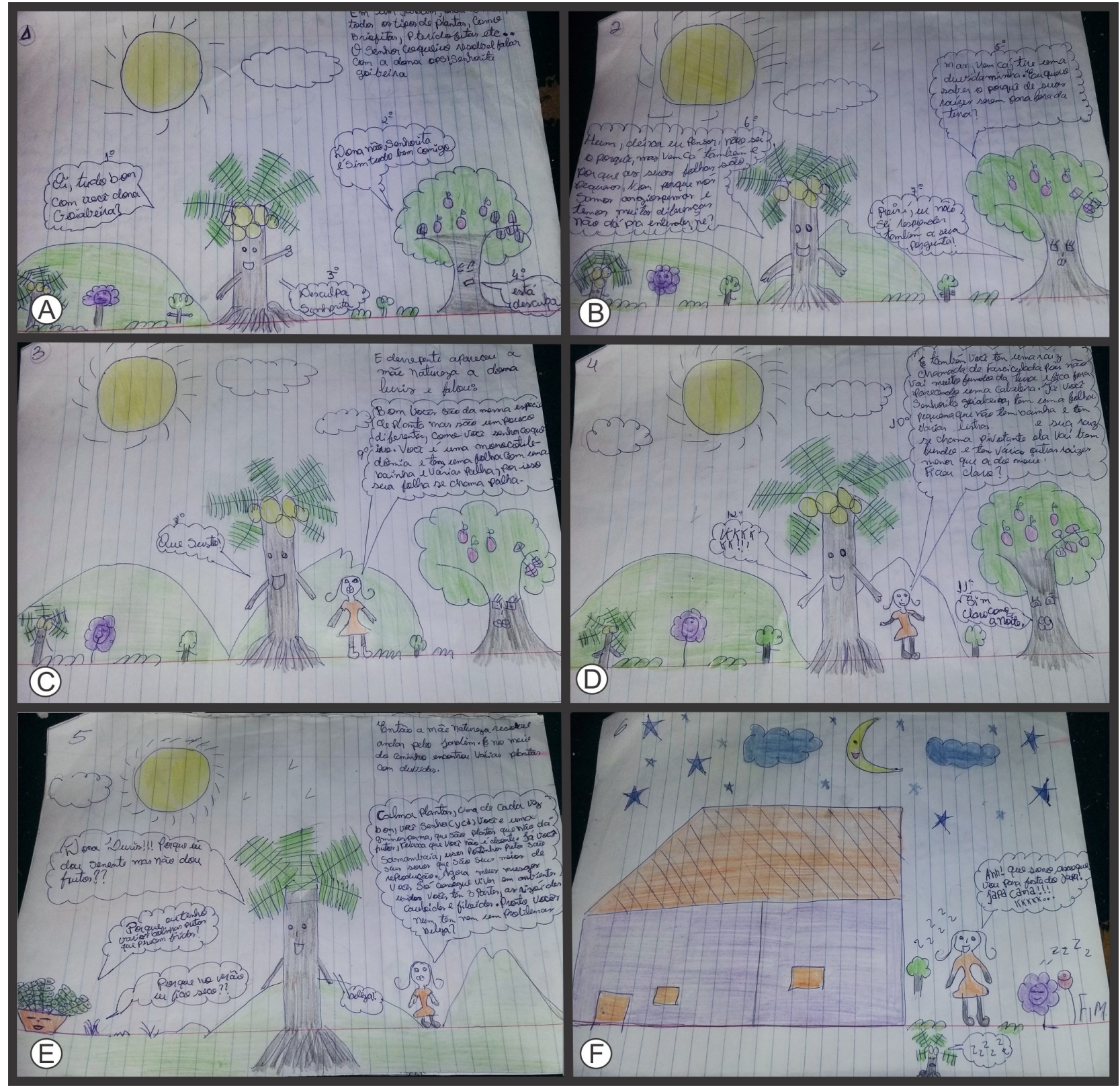

Figura 2. A: imagem da HQ produzida em folha com pauta (AL3); B e C: Imagem que ilustra as diferentes manifestações verbais; D: imagem ilustrando a dificuldade em usar termos científicos; E: imagem que ilustra o trecho em que o aluno AL3 conceituou corretamente os soros; F: imagem que ilustra o uso da linguagem utilizada no dia a dia dos adolescentes, contidos na HQ elaborada pelo AL3. 
Na maioria das histórias em quadrinhos produzidas pelos estudantes, os autores iniciaram suas histórias envolvendo os personagens em uma trama, com a finalidade de deixar o leitor sempre na expectativa, ansioso para saber o final da história.

As HQs pertencentes a AL1, AL2, AL4 dominaram perfeitamente estes elementos, elaborando suas HQs em uma sequência de tempo que foi possível desenvolver bem a trama sem que houvesse falha na comunicação e compreensão dos conceitos. O AL3 não desenvolveu a HQ utilizando uma trama, sua história teve como foco uma conversa em que todos os personagens foram envolvidos.

Tratando-se dos aspectos relativos ao estímulo da fantasia e da curiosidade detectouse que a ferramenta, além de despertar o interesse dos estudantes pela leitura, de modo geral, aguçou a fantasia e curiosidade dos leitores.

A história que mais respondeu este parâmetro (Tabela 1) foi a produzida pelo AL3. Nela estavam contidas, imaginação, criatividade e fantasia. Como exemplo pode-se mencionar quando utiliza as iniciais do nome da acadêmica monitora no Clube de Ciências junto às iniciais do nome da pesquisadora. "Luris" é o produto dessa junção e representa, na HQ do AL3 a mãe natureza. Além disso, o título da história é "A curiosidade não mata, tira dúvidas.", fazendo jus ao parâmetro.

E derrepente apareceu à mãe natureza a dona Luris e falou:_Bom vocês são da mesma espécie de plantas, mas são um pouco diferentes, como você senhor coqueiro, você é uma monocotiledônea e tem uma folha com uma bainha e várias palhas, por isso sua folha se chama palha (AL3).

Ao fazer a análise da relação entre a fala e o desenho, a ferramenta avaliativa constatou que as histórias em quadrinhos apresentaram duas linguagens fundamentais, a verbal e não verbal, a parte textual e os desenhos, reforçando um ao outro para que a mensagem fosse entendida. Os desenhos dos alunos não precisam ser perfeitos, basta apenas transmitir a informação com eficiência e relacionar-se com os elementos inseridos no roteiro (Vilela 2014).

Textos e desenhos fazem com que a leitura seja prazerosa, criando no leitor o desejo de ler. As HQs produzidas pelos alunos permitiram que eles relacionassem corretamente desenho e fala. Essa interação colaborou para o entendimento dos conceitos contidos nas histórias.

A interligação do texto com a imagem, existentes nas histórias em quadrinhos, amplia a compreensão de conceitos de uma forma que qualquer um dos códigos, isoladamente, teria dificuldade para atingir. $\mathrm{Na}$ medida em que essa interligação texto/ imagem ocorre nos quadrinhos com uma dinâmica própria e complementar, representa muito mais do que o simples acréscimo de uma linguagem a outra (Vergueiro 2014, p.22).

Essa relação permitiu detectar a importância desses elementos para que os conceitos fossem compreendidos. Os discentes desenharam elementos que deixaram suas histórias mais atrativas para a leitura e que ressaltaram as diferenças entre cada grupo de planta.

No contexto atual em que é necessário
reinventar aulas mais contextualizadas, em
um ambiente estimulante que garanta a
aprendizagem significativa, a história em
quadrinhos pode representar uma solução. A
HQ pode atender alguns destes requisitos,
como recurso didático, podendo ser uma
ferramenta para trabalhar diversas
disciplinas. Combinando linguagem verbal e
não verbal, a história em quadrinhos combina
imagens e textos escritos, de fácil
compreensão, articulando conteúdo com o
cotidiano (Neves 2012, p.17).

Durante a execução da tarefa de produzir os textos, foi possível constatar que a história em quadrinho, quanto ferramenta avaliativa, proporciona ao professor identificar a dificuldade de cada aluno, se houve aquisição do conteúdo abordado e se a ferramenta é bem aceita pelos alunos.

As HQs que permitiram que mostrassem a aceitação por parte dos alunos pertencem aos AL1, AL2, AL3 e AL4. Dois estudantes, contudo, não se mostraram efetivamente abertos a essa produção (AL5 e AL6) ao ponto de deixarem suas HQs inacabadas.

Um bom exemplo para expressar como as HQs permitiram a manifestação de conceitos apreendidos de diferentes maneiras está exposto nas Figuras $1 \mathrm{C}$ e D. Além do hábito diferenciado (arbustivo, arbóreo), que remete a padrões de crescimento distintos entre os 
grupos de plantas (no caso da figura, entre as pteridófitas e as gimnospermas e angiospermas), as diferenças reprodutivas entre os grupos de plantas também são destacadas (Figura 1I). Chama-se a atenção para a presença dos soros como estruturas relacionadas à reprodução nas pteridófitas.

Ao analisar a quantidade de conceitos utilizados nas HQs, detectou-se que a ferramenta avaliativa possibilitou o uso de um número considerável de conceitos, evidenciando que as atividades executadas no Clube de Ciências permitiram um avanço na retenção de conceitos na estrutura cognitiva dos estudantes.

As histórias elaboradas abordaram diferentes aspectos dentro da botânica, como tipo de raiz, folha, formas de reprodução. A história em quadrinho que abordou maior número de conceitos foi produzida pelo AL3, o mesmo utilizou nove conceitos em sua produção (Tabela 1). Os AL5 e AL6 não abordaram nenhum conceito, pois, conforme mencionado, não concluíram suas HQs.

A utilização de conceitos, contudo, não garantiu que suas aplicações estivessem corretas. Diante da análise feita sobre o número de conceitos empregados corretamente nas histórias em quadrinhos, notou-se que a ferramenta avaliativa foi de grande valia para sumarizar os conceitos abordados e assimilados corretamente pelos alunos.

$\mathrm{Na}$ HQ do AL3, há um trecho onde ele se referiu aos soros das samambaias como pontinhos pretos e que são seus meios reprodutivos. Apesar de não usarem termos científicos, o aluno conceituou corretamente, pois para Haven (2007), os soros são os esporângios que se agrupam na superfície inferior de uma fronde, em forma de linhas, pontos ou manchas amplas, na cor amarela, laranja, castanha ou preta (Figura 2E).

Quando o aluno descreveu a goiabeira (AL3), cometeu um equivoco, ao dizer que a folha da goiabeira tinha várias listras, na verdade suas folhas possuem nervuras, principal e secundária.

[...] Já você senhorita goiabeira, tem uma folha pequena que não tem bainha e tem varias listras, sua raiz se chama pivotante, ela vai bem funda e tem várias outras raízes menores que a do meio (AL3).
A HQ da AL1 apresentou seis conceitos abordados corretamente, porém, em um dos conceitos há uma contradição, pois primeiro diz que as samambaias não têm frutos, mas, se reproduzem pelos soros. Logo em seguida a AL1, diz que os soros são uma maneira de se desenvolver, conforme a figura $1 \mathrm{E}$.

Eu não tenho frutos, mas me reproduzo pelos soros. Vou explicar um por um, você esta vendo essa bolinha atrás das minhas folhas, isso que é soros, uma maneira de me desenvolver (AL2).

De acordo com Haven (2007), os soros são agrupamentos de esporângios encontrados na superfície inferior das folhas das samambaias, relacionadas à forma como as samambaia se reproduzem e não como elas se desenvolvem.

No que se refere à HQ desenvolvida pelo AL2, dentre os conceitos abordados corretamente, um deles referiu-se às fases de reprodução das briófitas, em que descreveu em uma das falas que as briófitas possuem duas fases reprodutivas, uma duradoura e uma passageira. De acordo com Raven,

\begin{abstract}
As briófitas consistem em três divisões de estrutura muito simples, plantas pequenas em que os gametófitos são sempre independentes nutricionalmente dos esporófitos, enquanto que os esporófitos são permanentemente ligados aos gametófitos e variam na sua dependência. Assim o gametófito é a geração dominante (Raven 2007, p.293).
\end{abstract}

Esta HQ foi a única em que todos os conceitos abordados foram utilizados corretamente e tinha como tema "As plantas também amam", explicando as diferenças existentes entre os grupos de plantas, estruturas e fases reprodutivas.

\footnotetext{
Seu musgo você é muito pequeno para mim, eu não dependo da água para me reproduzir e você precisa, não vive sem água. Eu tenho duas fases de reprodução, uma duradoura e outra passageira (AL2).
}

Já o AL4, na elaboração de sua HQ fez uso de seis conceitos certos. Como exemplo pode-se citar o momento em que coloca corretamente em sua HQ que a forma de 
dispersão nos pinheiros é feita pelos animais, pelo ser humano e pelo vento.

Bom, eu sou lindo, me reproduzo pelo estróbilo, minha raiz é pivotante,dou sementes e o que contribui para me reproduzir é o vento, os animais e o ser humano e faço parte das gimnospermas (AL4).

Dentre os conceitos errados, um deles foi abordado no tema: Gimnosperma e Angiosperma em o Romance. A AL4 ao falar que a gimnosperma, representada pelo pinheiro, completa uma angiosperma, representada pela laranjeira, cometeu um erro de aplicação conceitual, pois seus modos de reprodução são distintos, além disso, não dependem uma da outra para se reproduzir.

Após iniciarem suas histórias, ficou claro para os discentes que não é difícil aprender conceitos, por mais complexos que sejam, mas para isso, os professores devem utilizar ferramentas adequadas para atingir os propósitos por eles estabelecidos. "Para Vergueiro (2014, p.21) "'as histórias em quadrinhos aumentam a motivação dos estudantes para o conteúdo das aulas, aguçando sua curiosidade e desafiando seu senso crítico".

Ao produzirem as HQs, os alunos demonstraram um interesse maior pelo que foi trabalhado no Clube de Ciências no ano de 2014, começaram a perguntar, falar mais sobre o que aprenderam, discutir entre si sobre as formas de abordarem os conteúdos para que eles mesmos aprendessem, ao invés de memorizarem o conteúdo estudado. Essas produções textuais permitiram averiguar que a utilização da HQ, como ferramenta de avaliação, despertou o interesse dos alunos pelo assunto que estava sendo trabalhado. Para Menegolla \& Anna (1991, p.92):

O ensino fundamenta-se na estimulação, sendo esta favorecida pelos recursos didáticos, que facilitam a aprendizagem. Os recursos didáticos atuam no sentido de despertar o interesse, provocar a discussão e os debates; desencadeando perguntas e gerando novas ideias.

Percebeu-se que a ferramenta avaliativa contribuiu para que os alunos não utilizassem nenhum tipo de material didático, nem mesmo a internet como fonte de consulta, uma vez que deu liberdade para que expressassem apenas o que haviam aprendido. Assim, suas produções foram feitas em apenas três encontros e ao final de cada encontro as HQs eram entregues à pesquisadora.

Quanto à análise da consolidação do conhecimento durante a atividade, a ferramenta demostrou ser possível averiguar expressivamente a aquisição do conhecimento durante a produção da HQ. A utilização da HQ como ferramenta avaliativa, permitiu acompanhar o conhecimento consolidado pelos alunos detectando, por exemplo, que os conceitos mais frequentes nas HQs referiram-se ao ambiente em que vive cada grupo de plantas, suas diferenças e partes reprodutivas (Figuras $1 \mathrm{G}$ e $\mathrm{H}$ ). Todo conhecimento consolidado contribuiu para que aprendizagem não se tornasse mecânica.

As histórias em quadrinhos produzidas pelos alunos do Clube de Ciências permitiram detectar problemas e dificuldades enfrentadas, dentre os quais estão a pronuncia de nomes como briófitas, pteridófitas e gimnospermas. Outro fator a destacar é a questão do uso de analogias em alguns conceitos botânicos (Figura 2B).

Na HQ produzida pelo AL3, há uma parte em que ele, ao invés de utilizar o termo nervura, faz uso do termo listra para explicar um determinado conceito, demostrando a dificuldade de assimilação de termos científicos (Figura 2D).

Conforme mencionado anteriormente, dentre as HQs, apenas em duas não foi possível realizar a avaliação de todos os parâmetros, as HQs pertencentes a AL5 e AL6, que tiveram dificuldades na hora de organizar as ideias. Como a pesquisa coincidiu com um longo período da greve nas escolas, estes estudantes começaram a faltar os encontros, com isso, iniciaram suas HQs, mas não finalizaram.

Vale destacar que a HQ permitiu ainda verificar a desmotivação, desinteresse e até a insegurança de expor o que aprenderam. Devido a não finalização das suas respectivas histórias AL5 e AL6 responderam apenas um parâmetro (tabela 2, linha 1), referente à adequação do material.

Percebeu-se, com isso, a necessidade de diversificar as ferramentas avaliativas, pois a 
não conclusão desses dois alunos mostrou que nenhuma ferramenta é, por si só, suficiente para a diversidade de alunos que se tem em uma sala de aula. No caso de AL5 e AL6 a ferramenta não foi capaz de despertar o interesse deles, os quais permaneceram alheios aos avanços das histórias dos demais colegas. Nesse sentido, caberia ao professor sugerir outra ferramenta que os permitisse expressar seu aprendizado com maior segurança.

No entanto, a proposta de inserir novas ferramentas na sala de aula para avaliar a aprendizagem dos alunos deve ser planejada. $\mathrm{O}$ professor tem que ter em mente aquilo que ele quer que os alunos aprendam ou manifestem, verificando se a ferramenta a ser utilizada se adequa a realidade da escola e, principalmente, a do aluno.

\section{CONSIDERAÇÕES FINAIS}

Este trabalho de pesquisa utilizou a história em quadrinhos como ferramenta avaliativa a fim de evidenciar sua eficácia no processo avaliativo de ensino e aprendizagem dos alunos participantes do Clube de Ciências.

As histórias em quadrinhos elaboradas abordavam os conceitos botânicos estudados nos encontros realizados pelo Clube de Ciências no ano anterior, revelando o interesse dos alunos pela ferramenta. Os resultados apontam que as histórias em quadrinhos representam uma ferramenta eficaz para despertar e envolver os alunos a expor seu aprendizado e suas dúvidas de forma satisfatória e prazerosa. Ao averiguar a possibilidade da utilização da HQ como ferramenta avaliativa, percebeu-se que a mesma apresentou uma eficiência tanto para avaliar quanto para descobrir a potencialidade de cada aluno. A exposição dos conceitos estudados associando desenhos e falas permite ao professor a compreensão da real aprendizagem de cada estudante. A liberdade na construção das histórias e na aplicação livre da linguagem favorece a apresentação das ideias, superando a prática de reproduzir nos instrumentos avaliativos exatamente aquilo que o professor disse em sala de aula.

Logo, a realização de novas pesquisas que evidenciem a eficácia do Clube de Ciências na escola e a utilização de novos métodos avaliativos que meçam a aprendizagem de forma qualitativa e significativa, contribuirá para que novas ferramentas avaliativas sejam implantadas na escola.

\section{REFERÊNCIAS BIBLIOGRÁFICAS}

Barbosa, A. et al. 2014. Como Usar as Histórias em quadrinhos na sala de aula. 4. ed. São Paulo: Contexto, $155 \mathrm{p}$.

Fernandes, C. O. 2008. Currículo e Avaliação. Brasília: [s.n].

Menegolla, M. \& Sant'anna, I.M. 1991. Por que Planejar? Como Planejar? 15 ed. Petrópolis: vozes, $159 \mathrm{p}$.

Neves, S. C. 2012. A História em Quadrinhos como Recurso Didático em Sala de Aula. Monografia (Artes visuais) Universidade de Brasília, Palmas, Tocantins. $30 \mathrm{p}$

Rabelo, E.H. 2009. Novos tempos, novas práticas. 8 ed. Petrópolis ,Rio de Janeiro: Vozes, 144p.

Raven, P.H., Evert, R.F. \& Eichhorn, S.E. 2007. Biologia Vegetal, $7^{\mathrm{a}}$. ed. Coord. Trad. J.E.Kraus. Editora Guanabara Koogan, Rio de Janeiro.

Sant' Anna, I.M. 1995. Porque avaliar? como avaliar? critérios e instrumentos. 9 ed. Petrópolis, Rio de Janeiro: Vozes, 135p.

Silva, J. F. et al. 2013. Práticas avaliativas $e$ aprendizagens significativas: em diferentes áreas do currículo. 10 ed. Porto Alegre: Mediação, 128p.

Vasconcellos, C. S. 1998. Superação da Lógica Classificatória e Excludente da Avaliação - do "é proibido reprovar ', ao é preciso garantir a aprendizagem. São Paulo: Libertad, 125p.

Vergueiro, W. 2014. Uso das HQs no ensino. In: Barbosa, Alexandre (Org.). Como usar as Histórias em Quadrinho em Sala de Aula. 4 ed.Contexto, p.729.

Vilela, T. 2014. Os Quadrinhos na Aula de História. In: Barbosa, Alexandre (Org.). Como usar as Histórias em Quadrinho em Sala de Aula. 4 ed. Contexto, p.105-129. 